\title{
МОДЕЛЬ АНАЛИЗА ОТНОШЕНИЙ ЛИЧНОСТИ НА ОСНОВЕ «ПРИНЦИПА ОППОЗИЦИЙ»
}

\author{
Е.Б. СТАРОВОЙТЕНКО ${ }^{a}$, А.Н. ИСАЕВА
}

${ }^{a}$ Национальный исследовательский университет «Высшая школа экономики», 101000, Россия, Москва, ул. Мясницкая, д. 20

\begin{abstract}
Резюме
Исследования, посвященные отношениям личности, отличаются большим многообразием затронутых проблем, методологических и теоретических подходов, эмпирических результатов и значительными различиями в практической ценности открытых идей и разработанных методов. Среди этих исследований обнаруживается существенный пробел в плане построения строгих и целостных психологических моделей отношений, а также в плане структурного моделирования способов их изучения и интерпретации. Кроме того, в исследованиях отношений личности редко ставится проблема обнаружения оппозиций в их структуре, процессах и эффектах реализации, что существенно затрудняет понимание коллизий отношений, ресурсов их развития и условий их регресса. К числу малоисследованных проблем относятся многомерные, противоречивые связи отношений с культурой, определяющие их ценностный характер. В арсенале инструментов анализа отношений в индивидуальной диагностике, консультировании и психотерапии недостает аналитических моделей, ориентированных на выявление оппозиций, субъективное обращение с которыми влияет на динамику познавательной, этической, эстетической, творческой, рефлексивной активности личности в культуре и во взаимодействии с другими людьми. В перспективе развития психологического знания об отношениях личности необходимы обоснование новых взглядов на роль оппозиций в жизненном становлении ценностных отношений, разработка многовариантных теоретических и герменевтических моделей их анализа в аспекте «оппозиций», апробирование и валидизация моделей в работе с индивидуальными случаями, направленной на определение потенциалов развития отношений. Авторы статьи предлагают свою версию решения этих задач.
\end{abstract}

Ключевые слова: психология личности, модель, герменевтика, личность, отношения, жизнь, культура, ценности, оппозиции, рефлексия, обращение с оппозициями, динамика отношений.

Исследование, представленное в данной работе, посвящено проблеме построения теоретической модели анализа отношений личности с акцентом на оппозиции в их структуре и процессах реализации. Целью исследования стали поиск и систематизация дифференцированных бинарных параметров изучения ценностных отношений, связывающих личность с культурой. Разработка модели была ориентирована на ее 
применение в области исследовательской, герменевтической и практической психологии личности. Основой моделирования стала идея, согласно которой большой объем, содержательность, личностная значимость, разрешение и неразрешение противоречий между оппозициями в отношениях свидетельствуют о ведущем значении и наиболее «сильных возможностях» данных отношений в жизни личности. Замысел статьи выражает взгляд на динамику отношений, отличный от распространенного понимания, согласно которому их развитие предполагает сокращение числа или устранение оппозиций, а также необходимое разрешение их коллизий. Акцентируется момент удерживания, или «подвешивания», оппозиций, придающего отношениям напряженный, проблемный и при этом продуктивный характер. В статье рассматриваются ведущие категории аналитической модели отношений, раскрывается сущность «принципа оппозиций» в психологии, приводится система бинарных критериев анализа отношений. Кроме того, представлены результаты герменевтики оппозиций отношений, освещенных в рефлексивном тексте С. Дали, известного в качестве уникального творца культуры.

\section{Основные категории аналитической модели отношений}

В фокусе предпринятого нами теоретического моделирования находилась категория «отношения личности». В контексте исследования они определяются как динамичные образующие индивидуальной жизни, ее психологическая «ткань», активность, берущая начало в неосознаваемом самодвижении жизни, имеющая Я своим необходимым источником, устремленная в духовные области бытия и возвращаемая «себе» и «другим». Это напряжение, усилие сознания и самосознания; психические и практические связи с жизненными значимостями, имеющие сложную архитектонику; это ценностно-смысловые направленности, реализующиеся в формах познавательного, эстетического, этического, деятельно-творческого, рефлексивного и других отношений, релевантных, в частности, культуре европейского типа. Данный авторский взгляд на отношения личности предполагает их существование и развитие в качестве «жизненных», конституирующих жизнь личности в культуре, определяемых творческирефлексивной активностью Я.

В современных исследованиях личности необходимо глубже осмыслить роль индивидуальных отношений к объектам, ставшим для личности жизненными значимостями. Обрести значимости - поставить внешние и внутренние объекты, к которым влечет личность и которые обращены и «призывают» Я, в новые связи, поворачивать объекты в этих связях разными сторонами, выделять оппозиции в объектах, вычерпывать, постигать их ценные для Я содержания и функции, реализовать себя в природе, социуме, культуре посредством этих объектов.

В нашем понимании, укорененном в философском и общепсихологическом подходах, культура является миром высших ценностей и историей их личностных воплощений, а также 
мощным «инструментарием», творческим уровнем и критерием высшей результативности индивидуальной жизни. Кроме того, она выступает для личности «зеркалом» на пути узнавания и познания себя и других, средой внешних и внутренних отношений личности к произведениям и их авторам. Она в своей динамике создает особое «культурное» время протекания бытия и область воссоздания вечных всечеловеческих смыслов, становится сферой взаимных влияний и репрезентаций личностей, местом их предельного самовыражения (Старовойтенко, 2015).

В генетических, процессуальных, интер- и интрасубъектных связях с культурой жизненные отношения приобретают иенностный характер, выражающийся в их содержаниях, способствующих развитию личности, а также воссозданию и обновлению ее продуктивной жизни в мире. В обширной области психологического разграничения видов и типов отношений выделяется их дифференциация по ценностному основанию, осуществленная С.Л. Рубинштейном (1973). Основываясь на его идеях, мы предлагаем дифференциацию отношений и их аспектов по критериям ценностей, связанным с архитектоникой отношений, личностным обращением с их оппозициями, их диалогичностью, их представленностью в других людях, их преобразующими вкладами в мир, Я и культуру.

На наш взгляд (Старовойтенко, 2004), в познавательном отношении реализуются ценности обращения личности к тайнам и интеллектуальным вызовам мира; проблемного, исследовательского взгляда на мир; тонко дифференцированной психической организации индивидуального познания, включая зрелое дискурсивное мышление и развитую интуицию; ценности глубины, хорошей структурированности, анализа и синтеза оппозиций добываемого знания; эффективного межличностного интеллектуального обмена; умелого интеллектуального обращения с большими объемами информации; представленности личностного знания во внутреннем мире других; реализации творческого познания; создания интеллектуально емких текстов; персональных вкладов в культуру познания.

В әстетическом отношении реализуются ценности личностной интуиции, созерцания, образного представления красоты мира; поиска эстетического идеала; понимания прекрасного в природе, человеке, культуре; рефлексии и передачи другим людям своих эстетических впечатлений; воплощения открытой личностью красоты в текстах и изображениях; эстетизации отношения к себе и к Другому, своего персонального жизненного пространства, своей деятельности и способа построения жизни; осознания эстетического отношения как заключающего оппозиции и противоречия; эмоционально насыщенного проживания и оценки личностью своих значимостей в категориях гармонии, совершенства, изысканности; авторского самовыражения в искусстве.

В этическом отношении реализуются ценности личностного признания и утверждения жизни другого человека; переживаний принятия, любви, близости к другим людям; внимания, интереса, сопереживания 
и поддержки в адрес окружающих; знания этических канонов жизни в обществе; уважения достоинства и суверенности других; поступков добра, милосердия и помощи другим; осознания этических оппозиций и самостоятельного разрешения этических коллизий; личностных оценок себя и других в этическом измерении; занятия этических позиций при разрешении проблем познания, общения, деятельности, творчества и саморазвития; открытия своего этического присутствиях во внутренних мирах других людей; рефлексии событий причастности к высокой культуре жизни с другими людьми.

В деятельно-творческом отношении реализуются ценности активнопреобразующей связи личности с миром; практики освоения внешнего и внутреннего мира; разнообразия действий, служащих оперированию, воссозданию, созданию и сохранению предметов культуры; богатства способов применения орудий, инструментов, информационного обеспечения различных деятельностей; творчества и авторства личности; совместности творческих действий личности; внутреннего освоения эффективных действий других; рефлексии личностью своего творчества и его эффектов в сознании и деятельности других; раскрытия оппозиций в контексте творчества и нахождения уникальных соотношений между ними; воплощения творческой деятельности в продуктах, адекватных лучшим культурным традициям и современности; продления индивидуальной жизни в культуре посредством творческих вкладов личности и развития творческого опыта.
В рефлексивном отношении реализуются ценности личностного обращения к себе; индивидуального познания и понимания себя, своего мира, времени своей жизни; развития практик самопознания, оценки себя, осмысления себя, создания рассказа о себе, самодеятельности и самовыражения; совершенствования рефлексивных действий самоанализа, самообобщения, различения и соотнесения Я-оппозиций, синтеза Я; внутренних диалогов с собой; представления Я для себя во множестве ипостасей, ролей, общих жизнесостояний, своих «других Я»; знаний личности о своих свойствах и качествах, полученных на основе взаимодействия и представленности «в других»; осознания индивидуальности своих жизненных проблем, нахождения их аутентичных решений или внутреннего удержания коллизий в их «неразрешении»; интегральных переживаний, отмечающих самопознание: принятия себя, удовлетворенности собой, исполненности себя и своей жизненной состоятельности; индивидуального развития культуры самопознания в обществе.

Ценностный характер данных отношений позволяет личности всесторонне соединиться с культурой:

- переживать встречи с культурой как значимые события;

- принимать культурные ценности как свои значимости и действенные смыслы;

- осваивать содержательное богатство феноменов и практик культуры, а также разнообразие способов их личностной реализации, порождения и развития;

- раскрывать оппозиции, их связи, их напряженную конфликтность в культурной деятельности; 
- вступать во внешние и внутренние диалоги и полилоги с другими людьми в культуре;

- становиться в других людях «внутренними субъектами» культурной деятельности;

- рефлексивно и феноменологически обращаться с культурными ценностями-в-себе;

- быть причастным к культурному творчеству;

- сделать вклады в культуру и в индивидуальные миры других субъектов ценностных отношений;

- рефлексивно возвращать «Я-всебе» эффекты своей активности в культуре;

- видеть и осуществлять возможности переосмысления ценностных содержаний культуры и персональных связей с ней.

Каждый из этих моментов реализации отношений в культуре может стать основным предметом психологического исследования отношений. При этом выбранный предмет может стать доминантой при построении теоретической либо методологической модели отношений личности, или объектом герменевтического изучения образов и текстов культуры, посвященных отношениям, или объектом индивидуальной рефлексии и феноменологической практики в консультировании и самоисследовании личности.

В данном исследовании в качестве предмета изучения выделены оппозиции ценностных аспектов отношений, приведенных выше. Оппозиции отношений рассматриваются в исследовании как доминанта при разработке конщептуальной модели анализа отношений, как объект индивидуальной рефлексии выдающегося творца культуры в области изобразительного искусства, а также объект герменевтики его литературно-рефлексивного текста. В теоретическом и герменевтическом оперировании «противоположностями» важно было преломить психологический опыт развития «принципа оппозиций».

\section{«Принцип оппозиций» в психологии}

В контексте данного исследования «принцип оппозиций» определяется как основанный на различении, соотнесении и синтезе противоположностей способ поиска и организации знания, имманентный европейской культуре мышления и концептуально обоснованный в философской диалектике, различных гуманитарных науках, психологии (Адорно, 2003; Иванов, 1992, 2004; Ильенков, 1984; Холодная, 2004; Cole, Scribner, 1974; Jeffries, 2009). В частности, принцип оппозиций как прием репрезентации теоретического и получения эмпирического знания используется в психологии личности и психотерапии.

К.Г. Юнг в своих теоретических и герменевтических исследованиях выделил и разнообразно соотнес оппозиции душевной жизни личности (Юнг, 2001, 2005). С его точки зрения, душа человека имеет дуальную (или же четверичную) структуру, что отражено во всех его концептуальных построениях и постулируется в описании «архетипа противоречия», или Абраксаса (Юнг, 2009). Он предложил типологическую модель личности, основанием которой стали оппозиции сознательного - 
бессознательного, экстраверсии интроверсии, рационального - иррационального, мышления - чувства, ощущения - интуиции, маскулинности - фемининности. Каждая из этих бинарных пар представляет собой определенные способы «связей личности с жизнью» (Старовойтенко, 2015) или познания, самопознания, отношения и внутреннего обращения личности с действительностью. Способы активно взаимодействуют в режиме «энантиодромии» («встречного бега»), определяющем динамику индивидуальной души.

Согласно Юнгу, бинарность организации психической жизни личности представлена также бессознательными архетипами или априорными интегральными формами проживания, индивидуально воспроизводимыми во все эпохи и имеющими разнообразные эквиваленты в культуре. Эти формы имеют противоположные сущности и имена: Персона и Самость, Герой и Тень, Анима и Анимус, Мать и Отец, Божественный ребенок и Infant Terrible и т.д. Архетипические формы жизни актуализируются в проблемных ситуациях, обладающих особой значимостью для личности, в том числе потому, что имеют свои оппозиции.

Как пример успешного использования «принципа оппозиций» для систематизации теоретического знания о личности можно упомянуть работу С. Мадди (Maddi, 1968), предложившего в целях сравнения и последующего синтеза различных теорий личности разветвленную систему бинарных критериев, в основе которой лежит идея о «ядерной» и «периферической» личности. Анало- гично Л. Хьелл и Д. Зиглер (Hjelle, Ziegler, 1992) в качестве критериев оценки и сравнения теорий личности также предложили пары, названные «положениями о природе человека» и применимые не только методологически, но и при рефлексии имплицитной концепции личности, существующей у психолога.

Дж. Келли (Келли, 2000) в области когнитивной психологии личности разработал теорию бинарных «личностных конструктов». В конструктах представлены оппозиции, применимые при феноменологической характеристике личности (холодный - горячий, добрый - злой, близкий - далекий и т.п.). Кроме того, в теории Дж. Келли разработана система противоположных параметров для характеристики и классификации индивидуальных интеллектуальных конструктов: проницаемость и непроницаемость конструктов, всесторонние и частные, основные и периферические, жесткие и свободные, подчиняющие и подчиненные конструкты.

В области методических подходов к изучению личности, реализующих «принцип оппозиций», нужно прежде всего упомянуть семантический дифференциал Ч. Осгуда, направленный на прояснение семантических пространств личности посредством оценок объектов по бинарным параметрам. Оппозиции использованы также в построении шкал «Большой пятерки», «Гиссенского личностного опросника», «Q-сортировки», опросника Кейрси, факторов «Методики диагностики межличностных отношений Т. Лири», структуры опросника «Уровень субъективного контроля» и др. 
В сфере множественных психотерапевтических практик, адресованных личности, бинарные концепты используются в процессуальной терапии А. Минделла, созданной на основе идеи глубинной психологии о первичных и вторичных процессах психики. Оперирование оппозициями определяет особенности «диалектической психотерапии» (Смит, 2003; Linehan, 1993). Например, один из приемов этого подхода заключается в отстаивании терапевтом антитезиса к точке зрения клиента, в результате чего клиент и терапевт приходят к синтетическому выводу (Смит, 2003). «Терапия оппозициями» лежит также в основе провокативной терапии Ф. Фарелли (Фаррелли, Брандсма, 1996), высвобождающей здоровую часть личности клиента, способную к восстановлению ее адекватных персональных границ и нормальной социальной адаптации.

В современных исследованиях личности «принцип оппозиций» применяется при разработке сложных систем моделей, позволяющих интерпретировать и эмпирически изучать личность в новых интегральных парадигмах. К примеру, в монографии Е.Б. Старовойтенко «Персонология: жизнь личности в культуре» приводится множество «бинарных моделей», обосновывающих становление знания о личности в европейском культурогенезе. Автором также предложен метод экспликации «паттернов оппозиций», позволяющий осуществлять герменевтику взаимосвязанных противоречий личности в рефлексивных текстах культуры, а также моделировать индивидуальную рефлексию жизненных коллизий в контексте кон- сультирования и психотерапии (Старовойтенко, 2015).

«Принцип оппозиций» имеет достаточно широкое распространение в теоретико-методологических построениях психологов. Однако его потенциалы в психологии личности реализованы далеко не достаточно.

На наш взгляд, данный принцип имеет в познании личности следующие исследовательские возможности. Во-первых, это возможность рассмотрения широкого спектра индивидуальных свойств, форм активности, способов жизни с учетом их тонких континуальных переходов из одних качественных состояний в другие в большом диапазоне между противоположностями. Вовторых, возможность раскрыть в каждом аспекте личности признаки его противоположности. В-третьих, возможность исследовать личность в тенденциях к жизненному обновлению, изменению, развитию за счет взаимосвязей и взаимопереходов ее множественных оппозиций. В-четвертых, возможность выявить ограниченность генеза позитивных аспектов личности только при условиях объективного и субъективного исключения их регрессивных или негативных моментов. В-пятых, возможность нахождения новых источников и движущих сил развития личности на основе концептуального моделирования дифференцированной системы разнообразных действий с оппозициями, применимых в исследованиях, диагностике и индивидуальной рефлексии личности. В-шестых, возможность изучения путей достижения личностной зрелости при условиях большого объема жизненных оппозиций, разнообразия обращения 
личности со своими оппозициями и наличия, продления неразрешенных конфликтов между ними.

С нашей точки зрения, исследование оппозиций отношений личности состоит в выявлении закономерной внутренней двойственности любого аспекта отношения, противоречий между компонентами и тенденциями становления различных отношений, одновременности процессов и эффектов развития и регресса отношений, форм разрешения коллизий отношений, сочетающих конструктивные и деструктивные тенденции, разнообразия способов соотнесения оппозиций при разрешении противоречий отношений, особой активности личности, встроенной в любое отношение и состоящей в «отношении к своим оппозициям», развития отношения до уровня «зрелого» путем раскрытия и разрешения, наряду с неразрешением, его противоречий. Важную роль играет также определение доминирующих ценностных отношений личности не столько на основе яркой выраженности их позитивных аспектов, сколько на основе множественности заключенных в них оппозиций и искусства личности разнообразно оперировать ими, включая действия поляризации и поддержания напряжения между ними (Исаева, 2013, 2015; Старовойтенко, Исаева, 2010; Старовойтенко, 2015). Данный взгляд реализован нами при разработке и индивидуальном применении следующей модели анализа оппозиций личности.

\section{Модель анализа оппозиций в отношениях личности}

Приведем оппозиции, характерные и для отдельных ценностных отношений, и для их личностной структуры в целом, а также выделим условия возникновения противоречий между оппозициями и возможные способы их разрешения.

\section{Базовые оппозищии отношений}

- Направленность отношения во внешний и внутренний, объективный и субъективный мир личности;

- Психические и телесно-практические образующие отношения;

- Сознательный и бессознательный планы отношения;

- Сознательно-рефлексивные и сознательно-нерефлексивные образующие отношения;

- Рациональные с акцентом на мышление и иррациональные с акцентом на интуицию аспекты отношения;

- Эмоциональные и интеллектуальные аспекты отношения;

- Побудительные и действеннопродуктивные компоненты отношения;

- Отношение Я и отношение Других;

- Обращенность отношения к Я и к другим людям;

- Представленность отношения в Я и его отраженная представленность в Других;

- Результаты осуществления отношения в духовной и практической сферах жизни;

- Самодетерминация и детерминация отношения;

- Тенденции устойчивости и изменчивости отношения;

- Фемининные и маскулинные признаки отношения;

- Отраженные и не отраженные другими людьми аспекты отношения; 
- Известное и неизвестное в отношении;

- Возможное и действительное в отношении;

- Согласованность и рассогласование результатов реализации отношения с ценностными доминантами культуры.

\section{Оппозищии психологической архитектоники отношений}

- Ощущения - образные процессы;

- Абстрактно-логические процессы - вживание и созерцание;

- Дискурсивная мысль - понимание и постижение;

- Понятийное мышление - воображение и фантазия;

- Переживания - интеллектуальная активность;

- Речевая активность - невербальная экспрессия;

- Созерцание - практические действия;

- Рефлексия - самопереживание;

- Оппозиции различных стремлений или переживаний, или представлений, или мыслей, или высказываний, или действий, или рефлексивных актов.

\section{Оппозици качественного} становления отношений

- Зрелость - недостаточность развития;

- Позитивность - негативность;

- Конструктивность - деструктивность;

- Реалистичность - нереалистичность;
- Жизненная эффективность неэффективность;

- Обновление - стагнация;

- Многомерность - одномерность;

- Сложность - упрощенность;

- Проницаемость - непроницаемость для качественных влияний других отношений.

Оппозищии направлений становления отношений

- Развитие против регресса;

- Активность изменений против стагнации;

- Совершенствование против редукции;

- Усложнение против упрощения;

- Нормальное становление против патологического;

- Творческое обновление против адаптивных тенденций;

- Достижение зрелости против остановки в развитии.

\section{Общие ценностные оппозиции} отношений

- Развитие познавательного отношения в противовес отчуждению от познания;

- Развитие эстетического отношения в противовес нечувствительности и обесцениванию красоты;

- Развитие этического отношения в противовес сопротивлению позитивной этике жизни;

- Развитие деятельно-творческого отношения в противовес жизненной пассивности и разрушительной активности; 
- Развитие рефлексивного отношения в противовес уходу от самопознания.

\section{Оппозищии структуры отношений личности}

- Множество зрелых отношений в противоположность их незначительному количеству;

- Наличие нескольких ведущих отношений в противоположность одному доминирующему отношению;

- Сложность, множественность, оппозиционность связей между отношениями в противоположность слабому взаимодействию между отношениями;

- Развитие отдельных отношений на основе связей с другими в противоположность относительной автономии отношений;

- Обогащающие, усиливающие влияния отношений друг на друга в противоположность взаимным ограничениям и ослаблению отношений;

- Сходство психологической архитектоники различных отношений в противоположность их существенным различиям;

- Динамизация и интеграция отношений посредством активности субъекта в противоположность «бессубъектной» динамике структуры отношений;

- Большой объем осознанных оппозиций в отношениях в противоположность «одномерному» представлению личности о характере своих отношений;

- Наличие нескольких хорошо интегрированных отношений в структуре в противоположность отсутствию такого «интеграла»;
- Общая зрелость структуры отношений в противоположность зрелости отдельных отношений.

Как возникают противоречия между оппозициями отношений?

Динамика жизненных отношений представляет собой непрерывный процесс возникновения противоречий между взаимосвязанными оппозициями. Например, один из оппозиционных аспектов отношения значительно опережает в темпах становления другой аспект. Или один аспект приобретает качественный оттенок, исключающий его гармоничное единство с другим. Или один аспект испытывает изменения, несовместимые с состоянием другого. Или же один аспект достигает нового уровня развития, кардинально отличного от уровня другого. Или происходит редукция одного аспекта, хотя он необходим для полноценного существования другого. В этих и многих других случаях либо отчетливее обнаруживается закономерное различие оппозиций, либо начинается их расщепление и расхождение, либо появляется серьезный надлом их связи, либо совершается полная ломка взаимодействия, требующая перестройки одной из оппозиций или обеих сразу, либо встает проблема достижения равноценности оппозиций (Старовойтенко, 2004).

\section{Какими способами разрешаются} противоречия между оппозициями?

К основным из них можно отнести: установление относительного паритета оппозиций и развивающего взаимодействия между ними; нахождение 
новой меры соответствия в уровнях и направлениях развития оппозиций; достижение взаимодополнения в качествах и уровнях активности оппозиций; установление равновесия между оппозициями за счет их включения в новую систему взаимодействий; открытие новой формы положительного доминирования одной оппозиции над другой; отрицание одной из оппозиций за счет усиленного развития другой; «аннигиляция» одной оппозиции в другой; поляризация оппозиций и их удерживание во взаимном напряженном состоянии; уничтожение оппозиций; синтез оппозиций в качественно новом отношении личности (Старовойтенко, 2015).

Личность конструктивно разрешает противоречия отношений при взаимном обогащающем «вливании» и проникновении оппозиций, при их взаимном исключении в новом синтезе, при получении ими относительной самостоятельности на новом, более высоком уровне, при потере ими свойства быть оппозициями в кардинально преобразуемом отношении. Или в другом случае личность намеренно или спонтанно удерживает противоречия в «неразрешенном» состоянии, видя в этой напряженности жизненных отношений источник силы для их активизации и расширения.

\section{Каково назначение разработанной модели анализа отношений?}

Разработанная модель ориентирована на расширение теоретического знания о жизненных отношениях личности с акцентом на «оппозиции»; на эмпирический анализ отно- шений с точки зрения выявления множества их оппозиционных аспектов, задающих во взаимодействии те или иные направления становления личности; на герменевтический поиск в культуре критически сложных и полных индивидуальных вариантов реализации отношений в богатстве их противоречий; на разработку приемов рефлексии противоречий в проблемных отношениях личности, которые могут быть использованы в контексте психологического консультирования; на интерпретацию текстов консультативных сессий, а также текстов интервью и нарративов личности в психологической практике.

\section{Герменевтика оппозиций жизнен- ных отношений С. Дали}

В данной работе мы обосновываем герменевтическое назначение модели, обратившись к одному из опытов самопознания, воплощенных в знаменитых текстах культуры. Покажем, во-первых, как рефлексивное отношение автора конституирует Я на основе экспликации множества оппозиций, возникающих в различных ценностных отношениях. Вовторых, как отрефлексированные оппозиции неизмеримо расширяют пространство самосознания автора, где открываются уникальные варианты их коллизий, разрешения или «подвешивания» противоречий между ними. В-третьих, как автор текста совершает прорыв к принципиальной незавершенности «себя», поддерживает усилие по сохранению «самонапряжения», осуществляет создание новых возможностей рефлексивным текстом и перспектив 
«высвобождения жизни» при умножении, амплификации, разведении и сгущении оппозиций.

Предметом герменевтического исследования, основанного на применении намеченной модели анализа отношений и метода экспликации «паттернов оппозиций» (Старовойтенко, 2015), выступает рефлексивный текст художника Сальвадора Дали «Дневник одного гения» (Дали, 1999), признанный в мировой культуре уникальным опытом самораскрытия творца.

В качестве ведущих отношений Дали, нашедших выражение в «Дневнике», нами выделены эстетическое, творческое, этическое и рефлексивное отношения. Доминирующим среди них является эстетическое отношение. Его ведущая роль в рефлексивном и реальном жизненном пространствах автора определяется, на наш взгляд, общим объемом, разнообразием, эмоциональной насыщенностью, точностью осмысления и выражения, потенциалом и уникальностью оппозиций отношения.

Базовыми оппозищиями эстетического отношения Дали являются:

Сознательный и бессознательный планы отношения

1) Всю ночь я видел творческие сны, модельеру там хватило бы идей на семь сезонов, я мог бы разбогатеть! ↔ Но я забыл свой сон, и это стоило мне утрать этого маленького сокровища.

(Бессознательные образы красоты и невозможность их сознательного воплощения)

Отношение Я и отношение Других

2) Испокон веков люди одержимь манией постигнуть форму и свести ее к элементарным геометрическим объектам. ↔ И только Дали, поддавшись неповторимой магии носорога, нашел наконеи, истину.

(Тщетно ищущие идеальную форму другие и нашедший идеальную форму Я)

3) «Кружевнища» всегда считалась картиной, исполненной безмятежного покоя. ↔ Для меня она исполнена какой-то неистовой әстетической силь, как недавно открьтый антипротон.

(Каноническое восприятие известного произведения другими и уникальное ви́дение Я этого произведения)

Обрашенность отношения $\kappa Я и \kappa$ другим людям

4) Мы едем в Барселону, куда привезут мои эскизы декораций к балету. $\leftrightarrow$ Надеюсь, музыка будет достаточно скверной, тогда у меня будет возможность творить далианские чудеса в полном одиночестве.

(Создание произведения для других и процесс творения для себя)

Известное и неизвестное в отношении

5) Моя провидческая картина о смерти фюрера стоила мне анафемь со сторонь нацистов и бурных аплодисментов в стане их противников. $\leftrightarrow$ Я сам так и не понял окончательного смысла әтой картины.

(Понятное в созданном произведении и непонятое автором в нем)

Оппозищиями архитектоники әстетического отношения Дали являются:

Ошущения и образные процессы в отношении

6) Я пытался заставить засверкать на холсте отдельные чешуйки своей летающей рыбки и потому 
невозмутимо отдельвал тончайшие детали, не мигая намечал контуры чешуйки. ↔ Запах рыьбь, лежащей передо мной, стал таким зловонным, что меня чуть не вырвало съеденным завтраком.

(Образ красоты изображаемого и негативное ощущение от изображаемого)

Переживания и интеллектуальная активность в отношении

7) Я ошущаю приближение совершенства. $\leftrightarrow$ Оно все еще бесконечно далеко, как и все, что приближается.

(Переживание близости идеала и мысль о недостижимости идеала)

Созерцание и практические действия в отношении

8) Я должен сосредоточиться $и$ сегодня же закончить начатьй фрагмент картинь, затем приступить к «радиолуару» - земному шару, охваченному носорожьей тревогой. $\leftrightarrow$ Мне приходится стойко обороняться, чтобы не пустить бал Бейстегуи в вязкий поток моих грез.

(Реальная работа над произведением и перспектива своего растворения во внутренних образах)

Рефлексия и самопереживание в отношении

9) Мне казалось, что я весь покрылся чешуей и превратился в рыбу. $\leftrightarrow$ Это был мой опасный способ отождествиться с Христом, которого я тогда писал.

(Чувство перевоплощения в изображаемое и осознание рискованности этого приема творчества)

Оппозищи стремлений в отношении

10) Только бы мне избавиться от этой робости и начать писать без страха! ↔ Я стремлюсь $\kappa$ тому чтобы каждым своим мазком добиваться абсолюта.
(Стремление преодолеть страх творения и стремление превосходить себя в совершенстве произведений)

Оппозищии переживаний в отношении

11) В отрочестве мои эмочии были неопределенными и неясными. $\leftrightarrow$ Сейчас мои эмочии имеют совершенную форму..., олицетворяюшую нежность самой плоти Вселенной.

(Эстетически не оформленные переживания и эстетически оформленные переживания)

12) Видим, как с неба падает звезда, зеленая, как на полотнах Веронезе, самая крупная из всех, какие мне когда-либо приходилось видеть. $\leftrightarrow$ Гала - моя падаюшая звезда, самая конечная и самая ограниченная в пространстве!

(Переживание красоты вещи и переживание красоты женщины)

13) Цельй час прописанный мною фрагмент картинь поражал неземной красотой. $\leftrightarrow$ Потом он просох, $u$ все покрылось пятнами, потемнело, приобретя грязно-желтый цвет амбры. Вся моя жизнь после полудня была омрачена.

(Переживание красоты рождающегося изображения и переживание безобразия готового изображения)

14) Импровизированные певцы неожиданно возбудили во мне мощныцй прилив какой-то нежной $u$ страстной истомы. ↔ Но я бы приказал отдубасить их дубинкой разокдругой.

(Переживание наслаждения и агрессии в эстетическом моменте жизни)

Оппозициями качественного становления эстетического отношения Дали являются:

Конструктивность и деструктивность отношения 
15) Перед зрителями предстанут пять бельх лебедей. $\leftrightarrow$ Они взорвутся один за другим прямо у них на глазах.

(Создание эстетического образа и разрушение этого образа)

Реалистичность и нереалистичность отношения

16) Что бы невероятное я ни придумал, все в это верят. $\leftrightarrow$ Рано или поздно мой фантастический замысел внезапно становится реальностью.

(Изощренность эстетических фантазий и их превращение в реальность)

Оппозичиями эстетического отношения Дали в общей структуре отношений являются:

Оппозищи әстетического и рефлексивного отношений

17) Готовлю себя к погружению в грезы о бале Бейстегуи. ↔Я не мог приступить к этим моим горячо любимым галлючиначиям из-за непривычно грязного языка и побаливающей печени.

(Поиск эстетических наслаждений и осознание их ограничений со стороны собственного тела)

18) Я нарисовал шесть ангельских ликов неземной красоты. $\leftrightarrow$ Я от них совершенно обессилен и разбит.

(Эстетическое достижение и осознание страдания собственного тела)

Оппозици әстетического и этического отношений

19) Я готовился работать, сознавая, что должен использовать для этого каждую свободную минуту, так как я запаздываю с картиной. $\leftrightarrow$ Гала вдруг заявляет, что будет просто невероятно несчастной, если я не поеду с ней на әкскурсию на мыс Креус.

(Стремление завершить произведение и желание поддержать Другого в ущерб работе)
20) Я собирался разрешить себе наконеи погрузиться в грезы о бале Бейстегуи. ↔ Вдруг заявился какойто нотариус, который никак не хотел понять, что я занят.

(Стремление к наслаждению внутренним образом и восприятие Другого как помехи этому наслаждению)

21) Я вновь почувствовал, что Гала столь же прекрасна, как и существа, населяющие полотна Рафаэля. ↔ Но тут ко мне заявились два господина, оба идиоть по образу мыслей.

(Эстетическое восхищение Другим и обесценивание тех, кто не причастен к этому восхищению)

Эстетическое отношение Дали настолько интенсивно, что буквально пронизывает, создает, а иногда подрывает, основные связи Дали с жизнью: смещает границы воображения и реальности, нарушает и порождает культурные каноны, вступает в противоречия с социальными нормами, живительно и разрушительно вторгается в жизнь общества и конкретных людей, телесно обессиливает и преобразует художника. В тесной связи с данным отношением реализуется творческое отношение Дали.

Базовыми оппозициями творческого отношения Дали являются:

Рациональные и интуитивные аспекты отношения

22) Моим основным намерением было сделать чисто морфологчческий рисунок гения психоанализа. $\leftrightarrow$ Как выяснилось потом, в карандашном nортрете Фрейда я в точности обрисовал его земную смерть.

(Рациональное намерение и интуитивное прозрение в творчестве)

23) Гала скупала кисти, лаки и все прочее, что понадобится мне в тот 
день, когда я наконеи, всерьез займусь настоящей живописью. ↔Я шать не хотел ни о какой технике.

(Возможность техничного, рационального творчества и выбор интуитивного творчества «вне всякой техники»)

Побудительный и деятельно-продуктивный компоненты отношения

24) Когда я работал над картиной, мне хотелось овладеть недоступными вериинами мастерства, постигнуть саму суть, квинтәссенцию одухотворенности. ↔ Результат оказался просто катастрофический.

(Стремление к творческим высотам и реальные негативные результаты творчества)

Отношение Я и отношение Других

25) Филип, мой подмастерье, педантично и кропотливо трудится над моей картиной. $\leftrightarrow$ Мне останется только переделать все заново картина готова!

(Я в творчестве и Другой вне творчества)

26) Телевизионные комментаторы только и делали, что без кониа обсуждали мои эксперименты в области «булетизма». $\leftrightarrow A$ я в это время спал без просыпу, дабы в своих сновидениях найти наилучшую технику «блетизма».

(Я в своем творчестве и Другие о моем творчестве)

Проблемным, с выраженными деструктивными моментами, влияющими на другие (в частности, на эстетическое) отношения является этическое отношение Дали. Сосредоточенное на Другом или на Других, оно часто ориентировано на их обесценивание, унижение, отрицание.

Базовыми оппозичиями этического отношения Дали являются:
Представленность отношения в $Я$ и его представленность в Других

27) Я принял двух господ и снизошел до беседь, состоявшей из одних пошлостей. $\leftrightarrow$ За это был удостоен чрезвычайной признательности.

(Собственное отношение к Другим и оценка этого отношения Другими)

Оппозициями архитектоники этического отношения Дали являются:

Оппозичии переживаний в отношении

28) Я бунтовал против неистовой страсти Галь. ↔ Я научился поклоняться этой страсти.

(Переживание отвержения Другого и переживание принятия Другого)

29) Я продолжал расспрашивать Цвейга, показал ли он Фрейду мой портрет, это было бесконечно иенно для меня. ↔ Цвейг либо увиливал от ответа, либо был поглощен другими своими мыслями.

(Переживание доверия, близости Другого и переживание отчужденности Другого)

Оппозиции мыслей в отношении

30) Не страшитесь совершенства. $\leftrightarrow$ Оно вам нисколько не грозит.

(Идея совершенства человека и обесценивающая мысль о человеке)

Оппозициями качественного становления этического отношения Дали являются:

Позитивность и негативность отношения

31) Отеи был для меня человеком, которым я не только более всего восхищался, но и которому более всего подражал. $\leftrightarrow$ Что, впрочем, не мешало мне причинять ему многочисленнье страдания.

(Любовь к Другому и невыраженность ее в реальном отношении к нему) 
32) Заратустра казался мне героем грандиозных масштабов, чьим величием души я искренне восхищался. $\leftrightarrow$ Он сильно компрометировал себя в моих глазах тем, что я, Дали, уже давно перерос.

(Превознесение Другого и сомнения в достоинствах Другого)

Оппозициями этического отношения Дали в общей структуре его отношений являются:

Оппозищии әтического и рефлексивного отношений

33) Эти туристь глупь, добропорядочнь и спортивньь. $\leftrightarrow$ Я в их возрасте уже таскал с собою по палаткам Ницие и терзал мозги себе и другим.

(Обесценивание других людей и высокая оценка себя в сравнении с ними)

34) Приход друзей представляется мне как появление каких-то зыбких, призрачных осенних теней. $\leftrightarrow$ Все вокруг меркнет и тушуется, расступаясь перед нами - Галой и Сальвадором Дали.

(Отрицание силы и реальности бытия других людей и утверждение силы и реальности собственного бытия)

Оппозици этического и творческого отношений Дали

35) Умирая, мои друзья превращаются в таких ревностных далианцев, что станут трудиться у истоков моего творчества. $\leftrightarrow$ Мне кажется, что я виновен в их смерти .

(Принятие достижения славы творца ценой смерти других и переживание вины за это)

При герменевтическом анализе текста самопознания Дали обнаруживается большое значение его рефлексивного отношения, связанного и «встроенного» в другие отношения художника. Данное отношение «работает», прежде всего, на самообоснование исключительности и единственности Дали во всех значимых сферах его жизни: в творчестве, любви, почитании со стороны поклонников, в искусстве и среде великих. Другая важная направленность рефлексивного отношения - поиск возможностей своего субъективного времени для уникальных решений в изобразительном творчестве.

Базовыми оппозициями рефлексивного отношения Дали являются:

Сознательный и бессознательный плань отношения

36) Ницие был просто слабак, позволивший себе слабость сделаться безумием. ↔ Главное в таком деле как раз в том и состоит, чтобы не свихнуться!

(Я о власти бессознательного над сознанием и Я о силе сознания)

37) Какое наслаждение окунуться в праздность! ↔ Когда время особенно поджимает... Пусть накапливаются мои неутоленные творческие вожделения!

(Я в сознательной приостановке своего творчества и Я в обращении к творческим силам бессознательного)

Обрашенность отношения $\kappa$ Я $и к$ другим людям

38) Какое же наслаждение быть Сальвадором Дали! ↔ Не могу представить себе, как могут жить другие, если им не выпало счастье родиться Галой или Сальвадором Дали.

(Высокая оценка Я собственного уникального бытия и обесценивание им бытия других)

39) Восемьдесят юных дев просят меня показаться в окне мастерской $и$ хлопают мне в ладоши. $\leftrightarrow$ Я отхожу 
от окна и думаю, что же мне делать, как овладеть наконеи тайнами настоящего мастерства?!

(Принятие Я своей славы, признания другими и сомнения Я в своем мастерстве)

40) Трудно удерживать на себе напряженное внимание мира больше чем полчаса подряд. $\leftrightarrow$ Я же ухитрялся продельвать это цельх двадиать лет каждодневно.

(Я об ограниченности возможностей других и Я о безграничности собственных возможностей)

41) Критика - вещь возвышенная, ею достойны заниматься только гении. ↔ Единственный человек, который был способен написать памфлет про критику, - это я.

(Представление Я, что другие могут быть гениями, и убеждение Я в собственном превосходстве над гениями)

Известное и неизвестное в отношении

42) Нужно отьскать какие-либо убедительные теории, которье бы доказывали идею бессмертия. $\leftrightarrow$ Моя техника достигла такого совершенства, что я Әаже в мыслях не могу допустить такой нелепости, как собственная смерть.

(Поиск Я знания о бессмертии и таинственность для Я собственного будущего)

43) В Мексике умер человек, доживший до ста пятидесяти лет. Как бы мне хотелось превзойти этот возраст! ↔ Стойкость памяти, размягченные часы моей жизни, осознаете ли вы меня?

(Осознание Я возможного объективного времени жизни и незнание Я внутреннего времени собственной жизни)
Возможное и действительное в отношении

44) Я на пути к совершенству. $\leftrightarrow$ Но все должно стать еще лучше!

(Осознание Я действительного «достижения себя» и осознание нереализованных возможностей Я)

Оппозициями архитектоники рефлексивного отношения Дали являются:

Понятийное мышление и фантазия в отношении

45) Завтра 19 июля - день, когда мы с Галой прибыли сюда из Парижа в прошлом году. ↔ Значит, я еще не прибыл! Меня еще здесь нет. Я только завтра приеду в Порт-Льигат.

(Мысль Я о наступающем объективном времени своей жизни и фантазия Я об отставании субъективного времени)

Переживания и интеллектуальная активность в отношении

46) Я отдавал себе отчет в психопатологическом характере своих приступов безумия. $\leftrightarrow$ Я наслаждался тем, что наконеи-то подхватил самое настоящее безумие.

(Критическая мысль Я о своем бессознательном и наслаждение Я своим бессознательным)

47) Меня никогда не покидает ошущение, что все, что связано с моей персоной и моей жизнью, уникально и изначально отмечено печатью избранности, цельности, вызывающей яркости. $\leftrightarrow$ Я размышляю о колоритных прозвищах местных рыьбаков. Немного найдется в мире мест, где найдется сразу три Иисуса Xpucma!

(Переживание Я своей единственности и мысль Я о невозможности для других обладать ею)

48) $К$ вечеру я докопался до корней, до самьх истоков своих ошибок в 
живописи. ↔ Я наслаждался, смакуя эти ошибки.

(Критическое самопознание и переживание удовольствия от его процесса)

Созерцание и практические действия в отношении

49) Сквозь меня мало-помалу незаметно просачиваются недели. $\leftrightarrow$ Я цепляюсь за каждую каплю моего драгоченнейшего обожаемого времени.

(Созерцание Я своего субъективного времени и попытки Я активно владеть этим временем)

Оппозищии переживаний в отношении

50) В отрочестве я чувствовал себя униженным и подавленным перед романтически непостижимыми $u$ необъятными космическими пространствами. $\leftrightarrow$ Я благодарен современной физике за сибаритское и антиромантическое положение о том, что космос конечен.

(Переживание Я «малости себя» и переживание Я возможности своего величия)

51) Я снова женился на своей же собственной жене, на сей раз в лоне апостольской римской католической иеркви. $\leftrightarrow$ Через четверть часа я ошу тил пронзительное, неистовое желание снова, еще раз жениться на Гале.

(Переживание Я уже свершившегося в своей жизни и переживание Я еще не свершившегося в жизни)

Ведущие отношения С. Дали в их взаимосвязях имеют «ядро жизненного напряжения», образованное неразрешенными коллизиями оппозиций, общих для данных отношений. Это оппозиции сознания и бессознательного в отношениях, оппозиции обращенности отношений к Я и Другим, оппозиции известного и неизвестного в отношениях, оппозиции позитивного и негативного качества отношений, оппозиции противонаправленных переживаний. Связывая отношения единым контуром динамизации, они создают коллизии эстетического и этического, творческого и этического, рефлексивного и этического, эстетического и рефлексивного отношений. На этой основе в индивидуальной жизни и самосознании художника, в его душевной глубине, поступках любви и творчества воссоздаются силы сохранения, проблематизации и обновления культуры.

\section{Литература}

Адорно, Т. В. (2003). Негативная диалектика. М.: Научный мир.

Дали, С. (1999). Дневник одного гения. М.: ЭКСМО-Пресс.

Иванов, В. В. (1992). Нечет и чет. Асимметрия мозга и динамика знаковых систем. В кн. В. В. Иванов, Избранные труды по семиотике и истории культуры (с. 381-604). М.: Языки русской культуры.

Иванов, В. В. (2004). К семантической типологии производных от числительного «два». В кн. Сокровенные смыслы: Слово. Текст. Культура. Сборник статей в честь Н.Д. Арутюновой (с. 101-111). М.: Языки русской культуры.

Ильенков, Э. В. (1984). Диалектическая логика. М.: Политиздат.

Исаева, А. Н. (2013). «Принцип оппозиций» в персонологическом познании. Психология. Журнал Высшей школы экономики, 10(1), 135-149. 
Исаева, А. Н. (2015). Субъект жизни в отношении к оппозициям. Мир психологии, 83(3), 161-173. Келли, Дж. (2000). Теория личности: психология личностных конструктов. СПб.: Речь. Рубинштейн, С. Л. (1973). Проблемъ общей психологии. М.: Просвещение.

Смит, Н. (2003). Современные системы психологии. СПб.: Прайм-ЕВРОЗНАК.

Старовойтенко, Е. Б. (2004). Психология личности в парадигме жизненных отношений. М.: Академический проект.

Старовойтенко, Е. Б. (2007). Культурная психология личности. М.: Академический проект.

Старовойтенко, Е. Б. (2015). Персонология: изнь личности в культуре. М.: Академический проект. Старовойтенко, Е. Б., Исаева, А. Н. (2010). Роль противоречий в жизни личности. Мир психологии, 66(2), 230-241.

Фаррелли, Ф., Брандсма, Дж. (1996). Провокационная терапия. Екатеринбург: Издательство «Екатеринбург». Режим доступа: http://www.koob.ru/farrelly_bradsma/provakatsionnaya_terapiya Холодная, М. А. (2004). Когнитивные стили: о природе индивидуального ума. СПб.: Питер.

Юнг, К. Г. (2001). Психологические типы. М.: Азбука.

Юнг, К. Г. (2005). Душа и миф: шесть архетипов. М.: АСТ.

Юнг, К. Г. (2009). Красная книга. Liber Novus. М.: Касталия.

Cole, M., \& Scribner, S. (1974). Culture and thought: A psychological introduction. New York: Wiley and Sons.

Hjelle, L, \& Ziegler, D. (1992). Personality theories: Basic assumptions, research, and applications (3th ed.). New York: McGraw-Hill.

Jeffries, L. (2009). Opposition in discourse: The construction of oppositional meaning. London: Continuum.

Linehan, M. M. (1993). Cognitive behavioral treatment of borderline personnality disorder. New York: Guilford Press.

Maddi, S. R. (1968). Personality theories: a comparative analysis. Homewood, IL: Dorsey Press.

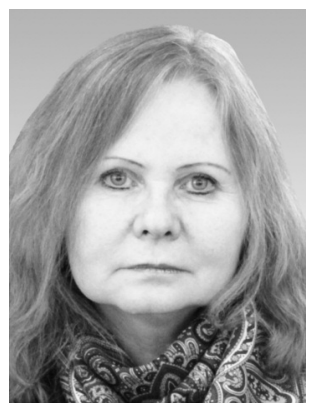

Старовойтенко Елена Борисовна - заведующая кафедрой, факультет социальных наук, департамент психологии, кафедра психологии личности, Национальный исследовательский университет «Высшая школа экономики», доктор психологических наук, профессор. Сфера научных интересов: методология психологии, теоретическая психология личности, психология познания, психология рефлексии. Автор концепции жизненных отношений личности, концепции культурной психологии личности, моделей персонологии жизни и персонологии Я.

Контакты: helestaOS@yandex.ru

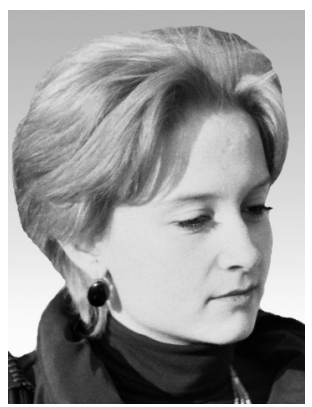

Исаева Анастасия Николаевна - преподаватель, факультет социальных наук, департамент психологии, кафедра психологии личности, Национальный исследовательский университет «Высшая школа экономики».

Сфера научных интересов: методология психологии личности, персонология, психология жизненных отношений личности, отношение личности к оппозициям жизни и противоречиям, герменевтика. Контакты: aisaeva@hse.ru 


\title{
The Model of Analysis of Personal Relationships on the Basis of "Oppositional Principle"
}

\author{
E.B. Starovoytenko ${ }^{a}$, A.N. Isaeva ${ }^{a}$
}

${ }^{a}$ National Research University Higher School of Economics, 20 Myasnitskaya Str., Moscow, 101000, Russian Federation

\begin{abstract}
The studies on personal relationships differ by the large diversity of the topics touched, methodological and theoretical approaches, empirical results and significant differences in practical value of discovered ideas and developed methods. The important gap is found among these studies though. This gap lies in construction of strict and holistic psychological models of relationships as well as in structure modeling of ways of their research and interpretation. Also the problem of oppositions in the structure of relationships and their processes and effects of realization poses very rarely in studies of relationships. It makes difficult to understand the collision of relationships, resources of their development and conditions of regress. The multidimensional and contradictory ties of relationships with culture, which define their axiological character, are among the unexplored issues. Subjective treatment of oppositions influences the dynamics of cognition, ethical, esthetic, creative, reflective activity of personality in culture and in communication with other people. The analytical models, oriented to explication of these oppositions of relationships, are scarce among the tools of analysis of relationships in personal diagnostics, counseling and psychotherapy. The grounding of new points of view on the role of oppositions in life formation of axiological relationships, on elaboration of multivariate theoretical and hermeneutical models of analysis of relationships' oppositions, on approbation and validation of models in the practice of individual cases, focused on detection of potentials of relationships' development are needed in the perspective of evolution of psychological knowledge about personal relationships. The authors offer their own way to solve these tasks.
\end{abstract}

Keywords: personality psychology, model, hermeneutics, personality, relationships, life, culture, values, oppositions, reflection, treatment of oppositions, dynamics of relationships.

\section{References}

Adorno, Th. W. (2003). Negationaya dialektika [Negative dialectics]. Moscow: Nauchnyi Mir. (Transl. of: Adorno, Th. W. (1966). Negative Dialektik [Negative dialectics]. Frankfurt am Main: Suhrkamp. (in German)).

Cole, M., \& Scribner, S. (1974). Culture and thought: A psychological introduction. New York: Wiley and Sons. Dali, S. (1999). Dnevnik odnogo geniya [Diary of a genius]. Moscow: EKSMO-Press. (Transl. of: Dalí, S. (1963). Journal d'un günie [Diary of a genius]. Paris: Gallimard. (in French)).

Farrelly, F., \& Brandsma, J. (1996). Provokatsionnaya terapiya. Ekaterinburg: Izdatelstvo "Ekaterinburg". Retrieved from http://www.koob.ru/farrelly_bradsma/provakatsionnaya_ter- 
apiya (Transl. of: Farrelly, F., \& Brandsma, J. (1973). Provocative therapy. Fort Collins, CO: Shields Publishing).

Hjelle, L, \& Ziegler, D. (1992). Personality theories: Basic assumptions, research, and applications (3th ed.). New York: McGraw-Hill.

Ilyenkov, E. V. (1984). Dialekticheskaya logika [Dialectical logic]. Moscow: Politizdat.

Isaeva, A. N. (2013). The "Opposition principle" in personological cognition. Psychology. Journal of Higher School of Economics, 10(1), 135-149. (in Russian)

Isaeva, A. N. (2015). Sub"ekt zhizni v otnoshenii k oppozitsiyam [Subject of life in a relationship to oppositions]. Mir Psikhologii, 83(3), 161-173. (in Russian)

Ivanov, V. V. (1992). Nechet i chet. Asimmetriya mozga i dinamika znakovykh sistem [Odd and even. Brain asymmetry and dynamics of semiotic systems]. In V. V. Ivanov, Izbrannye trudy po semiotike $i$ istorii kultury [Selected works on semiotics and history of culture] (pp. 381-604). Moscow: Yazyki Russkoi Kul'tury.

Ivanov, V. V. (2004). K semanticheskoi tipologii proizvodnykh ot chislitel'nogo "dva" [On semantic typology of derivatives from numeral "two"]. In Sokrovennye smysly: Slovo. Tekst. Kul'tura. Sbornik statei v chest' N.D. Arutyunovoi [Hidden meanings: Word. Text. Culture. Collected works in honor of N.D. Arutyunova] (pp. 101-111). Moscow: Yazyki Russkoi Kul'tury.

Jeffries, L. (2009). Opposition in discourse: The construction of oppositional meaning. London: Continuum.

Jung, C. G. (2001). Psikhologicheskie tipy [Psychological types]. Moscow: Azbuka. (Transl. of: Jung, C. G. (1921). Psychologische Typen [Psychological types]. Zurich: Rascher Verlag. (in German)).

Kelli, G. (2000). Teoriya lichnosti:psikhologiya lichnostnykh konstruktov [The theory of personality: The psychology of personal constructs]. Saint Petersburg: Rech'. (Transl. of: Kelly, G. A. The psychology of personal constructs. London: Routledge).

Kholodnaya, M. A. (2004). Kognitivnye stili: o prirode individual'nogo uma [Cognitive styles: On the nature of individual mind]. Saint Petersburg: Piter.

Linehan, M. M. (1993). Cognitive behavioral treatment of borderline personnality disorder. New York: Guilford Press.

Maddi, S. R. (1968). Personality theories: a comparative analysis. Homewood, IL: Dorsey Press.

Rubinstein, S. L. (1973). Problemy obshchei psikhologii [Problems of general psychology]. Moscow: Prosveshchenie.

Smith, N. (2003). Sovremennye sistemy psikhologii [Current systems in psychology]. Saint Petersburg: Praim-EVROZNAK. (Transl. of: Smith, N. W. (2001). Current systems in psychology: History, theory, research, and applications. Belmont, CA: Wadsworth).

Starovoytenko, E. B. (2004). Psikhologiya lichnosti v paradigme zhiznennykh otnoshenii [The psychology of personality in a paradigm of life relationships]. Moscow: Akademicheskii Proekt.

Starovoytenko, E. B. (2007). Kul'turnaya psikhologiya lichnosti [The cultural psychology of personality]. Moscow: Akademicheskii Proekt.

Starovoytenko, E. B. (2015). Personologiya: zhizn' lichnosti v kul'ture [Personology: Life of personality in culture]. Moscow: Akademicheskii Proekt.

Starovoytenko, E. B., \& Isaeva, A. N. (2010). Rol' protivorechii v zhizni lichnosti [The role of oppositions in the life of personality]. Mir Psikhologii, 66(2), 230-241. (in Russian)

Yung, K. G. (2001). Psikhologicheskie tipy [ Psychological types]. Moscow: Azbuka. 
Yung, K. G. (2005). Dusha i mif: shest' arkhetipov [Sole and myth: six archetypes]. Moscow: AST. (Transl. of: Jung, C. G. (1970). Four archetypes: Mother, Rebirth, Spirit, Trickster. Princeton, NJ: Princeton University Press).

Yung, K. G. (2009). Krasnaya kniga. Liber Novus [The red book. Liber Novus]. Moscow: Kastaliya. (Transl. of: Jung, C. G. (2009). The Red Book. Liber Novus. New York: Philemon Series/W.W. Norton \& Co).

Elena B. Starovoytenko - head of the department, School of Psychology, Faculty of Social Sciences, Department of Psychology of Personality, National Research University Higher School of Economics, D.Sc., professor.

Research area: methodology of psychology, theoretical psychology of personality, psychology of cognition, psychology of reflection.

E-mail: helestaOS@yandex.ru

Anastasia N. Isaeva - lecturer, Faculty of Social Sciences, School of Psychology, Department of Psychology of Personality, National Research University Higher School of Economics.

Research area: methodology of personality psychology, personology, psychology of life relationships of personality, personal relationship to the life oppositions and contradictions, hermeneutics. E-mail: aisaeva@hse.ru 